\title{
Correction to: Between fragmentation and institutionalisation: the rise of migration studies as a research field
}

Nathan Levy*, Asya Pisarevskaya and Peter Scholten

* Correspondence: levy@essb.eur.nl The original article can be found online at https://doi.org/10.1186/ s40878-020-00180-7

Department of Public Administration and Sociology, Erasmus University Rotterdam, Rotterdam, Netherlands

\section{Correction to: Comparative Migration Studies 8, 24 (2020) https://doi.org/10.1186/s40878-020-00180-7}

Following publication of the original article (Levy, Pisarevskaya, \& Scholten, 2020), the authors reported several errors.

In the Abstract, "co -authorships" has been corrected to "co-authorships".

Footnote 1 contained a typesetting mistake - duplicate text was added. It has been corrected to: "E.g. a transdisciplinary article is one where it becomes difficult to ascertain the discipline from which it has originated, even though it is clearly identified as belonging to migration studies."

In the section 'Bibliometric analysis', the formula has been corrected to:

$$
P_{t}=\frac{N_{t} *\left(N_{t}-1\right)}{2}, \text { where } \mathrm{N} \text { is a Total number of sources for period } t .
$$

The 8th paragraph of the 'Bibliometric analysis' contained a typesetting mistake - the first part (highlighted in bold typeface) was omitted. This paragraph has been corrected to: "We did this in five year increments $(1975-1979 ; 1980-1984$, and so on, with the exception of the final period, 2015-2018). The network files exported from VOSviewer can be found in the Harvard Dataverse (see Levy, Pisarevskaya, \& Scholten, 2020). Following our iterative logic, this enabled us to analyse the data in the same terms - i.e. "early 1980s", "late 1990s" - as our interviewees described their perception of the field's development. VOSviewer clusters the authors according to how often they are cited together. We take these clusters to approximate the variety of epistemic communities within the field in each period. To assign labels, we used Google Scholar to find the unifying features of each cluster. We checked the research of each cluster's most-cited authors, and the first-page results (usually the authors' higher-cited works) enabled us to grasp their conceptual, thematic, or disciplinary focus. We triangulated this information with the reflections shared by our expert interviewees."

(c) The Author(s). 2020 Open Access This article is licensed under a Creative Commons Attribution 4.0 International License, which permits use, sharing, adaptation, distribution and reproduction in any medium or format, as long as you give appropriate credit to the original author(s) and the source, provide a link to the Creative Commons licence, and indicate if changes were made. The images or other third party material in this article are included in the article's Creative Commons licence, unless indicated otherwise in a credit line to the material. If material is not included in the article's Creative Commons licence and your intended use is not permitted by statutory regulation or exceeds the permitted use, you will need to obtain permission directly from the copyright holder. To view a copy of this licence, visit http://creativecommons.org/licenses/by/4.0/. 
Footnote 2 contained a typesetting mistake - duplicate text was added. It has been corrected to: "See sheet 'all countries weighted' for relativized co-authorship statistics."

In the 9th paragraph of the "Bibliometric analysis', "co -citation" has been corrected to "co-citation".

In the 2nd paragraph of the 'Disciplines and cross-disciplinary osmosis', "most -cited" has been corrected to "most-cited".

In the 5th paragraph of the 'Disciplines and cross-disciplinary osmosis', "Pennix" has been corrected to "Penninx".

The 5th paragraph of the 'Conclusion and discussion: fragmentation and institutionalisation in the field of migration studies' section contained a typesetting mistake - the phrase "that refer to" was duplicated. The duplicated phrase was removed.

The original article (Levy et al., 2020) has been corrected with regards to the above errors.

Published online: 24 August 2020

Reference

Levy, N., Pisarevskaya, A., \& Scholten, P. (2020). Between fragmentation and institutionalisation: the rise of migration studies as a research field. Comparative Migration Studies, 8, 24 https://doi.org/10.1186/s40878-020-00180-7. 